\title{
"All in this together": The global duty to contribute towards combating the Covid-19 pandemic
}

\author{
JEFF D'SOUZA, EUNICE KAMAARA, DAVID NDERITU
}

\begin{abstract}
This paper explores the unique realities and effects of Covid-19 as experienced in the global North and global South with special reference to Canada and sub-Saharan Africa; it also examines the moral responsibilities countries have towards their own people and the duty they have to work together to minimise and mitigate the devastating effects of the pandemic worldwide. We illuminate the importance of countries sharing their own world views, strengths, and expertise, and learning from one another in order to better situate all in tackling the pandemic. We argue that it is only insofar as all countries work collaboratively commensurate to each party's capacity to contribute towards the tackling of the Covid-19 pandemic that we may truly be said to be "all in this together".
\end{abstract}

Keywords: Covid-19, global North, global South, solidarity, subSaharan Africa, global health

\section{Introduction}

With over 218 million reported cases of the novel coronavirus disease (Covid-19) and approximately 4.5 million related deaths as of September 1, 2021 (1), we have been facing one of the greatest threats to human beings ever. Indirectly, millions of more lives are lost due to disruptions in healthcare programmes, which threaten decades of progress in combating maternal and child mortality, tuberculosis, malaria, HIV, polio, and various non-communicable diseases (2). Anxiety, depression, suicide, drug abuse, and physical abuse are also on the rise as the political and socioeconomic upheaval related to the pandemic continues $(3,4)$.

Authors: Jeff D'Souza (corresponding author - jdsouza@integrityinethics.ca), Senior Ethicist, Integrity in Ethics; Research Associate, Department of Philosophy, McMaster University, Ontario, CANADA; Eunice Kamaara (ekamaara@gmail.com), Moi University, Eldoret, KENYA; David Nderitu (david.nderitu@egerton.ac.ke), Egerton University, Egerton, KENYA

To cite: D'Souza J, Kamaara E, Nderitu D. "All in this together": the global duty to contribute towards combating the Covid-19 pandemic. Indian J Med Ethics. 2022 Jan-Mar; 7(1) NS: 42-47. DOI: 10.20529/IJME.2021.078.

Published online first on October 13, 2021.

Manuscript Editor: Sunita Sheel Bandewar

Peer Reviewer: Raffaella Ravinetto

(c) Indian Journal of Medical Ethics 2022
The Covid-19 pandemic requires global and unified action whereby governments, scientists, and industry share information and resources and work together to mitigate its devastating effects. To promote this, leaders of countries, the World Health Organization (WHO), the Red Cross, and Médecins Sans Frontières have underscored that we are "all in this together" $(2,5,6)$. While such appeals to solidarity are helpful in generating consensus and promoting a more unified response, it is unclear what a commitment to solidarity entails. We contend that an essential element of "all in this together" is a commitment to support and learn from each other.

This paper explores the unique experiences of Covid-19 in the global North (specifically in Canada) and the global South (with a focus on sub-Saharan Africa) and, thereafter, examines the moral responsibilities of both high-income countries (HICs) and low- and middle-income countries (LMICs) in working together to minimise the devastating effects of the pandemic worldwide. With the unique abilities and experiences of the global North and the global South, each could learn and gain from the other. Only then, would both be considered to have achieved solidarity.

\section{Living through the global pandemic in the global North and global South}

While a proper response to the Covid-19 pandemic requires paying attention to the devastating effects of the disease worldwide, it is also important to acknowledge the ways in which particular regions, countries, and communities are uniquely affected. Often, we become fixated on aggregate numbers and do not pay enough attention to the experiences of the individuals behind those numbers. In this section, we shed light on the different effects of Covid-19 in Canada and in sub-Saharan Africa. We choose Canada because: (i) Canada has been significantly affected by the global pandemic, (ii) it is a high-income country capable of providing aid to both its own people and other nations, and (iii) Canada has taken steps to address the needs of Canadians affected by the pandemic.

\section{On Canada}

There have been approximately 1.5 million cases of Covid-19 and 27,000 deaths in Canada, out of a population of nearly 
38 million people, as of September 5, 2021 (7). Of course, the indirect effects of the pandemic, such as closed borders, school closures, job losses, and the grieving of individuals, have affected the majority of Canadians. While the provinces of Ontario and Quebec have been hardest hit, those individuals living in long-term care (eg, nursing homes) have experienced the most devastating effects, accounting for $82 \%$ of Covid-19 deaths (8).

Canada has a fairly robust and integrated universal healthcare system, where the healthcare needs of Canadians are met free of charge. Prior to the peak of the first wave, many hospitals revamped entire units and built new hospital wings to promote access to quality care (9). Additionally, both private and public spheres are working together with the health industry to minimise the effects of Covid-19; for example, flight simulation companies have manufactured and supplied more than 10,000 ventilators, and breweries have shifted production from beer to hand sanitisers $(10,11)$.

Shortly after the WHO declared Covid-19 a global public health emergency, the government of Canada moved quickly to minimise the devastating effects on individuals. For example, individuals who had lost their jobs due to the pandemic would receive $\$ 2,000$ (CAD) every four weeks, home-owners unable to pay their mortgage were allowed to defer their payments, various low-wage essential workers received top-up pay, federal student loans and interest payments were frozen, and people with disabilities, parents with young children, and seniors received additional payments (12). There have also been investments made to support the most vulnerable and marginalised groups, including the homeless, temporary residents, refugees, temporary foreign workers, women and children fleeing violence, youth struggling with mental health issues, and Indigenous populations $(12,13)$. Covid-19 vaccines have been made available to front-line workers, individuals in long-term care, and Indigenous populations, and are now being planned for the rest of the populations $(12,13)$. While more could always be done to mitigate further setbacks due to Covid-19, much is being done in Canada.

Combined Covid-19 management measures have made it possible for the majority of Canadians to either work in their usual environments with additional safeguards, work from home, or receive pay (through employment insurance) to stay home until they are able to find work. This snapshot of what it is like to live in Canada during the Covid-19 pandemic is in stark contrast to the experience of many people across the world, especially in LMICs, where health systems are often poorly integrated, resources sometimes limited, standards of living relatively low, and where governments are often unable to provide adequate support to their people (14).

\section{Across sub-Saharan Africa}

While the capacity of healthcare systems across sub-Saharan Africa vary from country to country, generally, African health systems are among the most poorly-funded and thinlystaffed in the world $(15,16)$. For example, in sub-Saharan Africa, the health expenditure per capita is $\$ 83.76$ USD, while the world's per capita spending is $\$ 1,061$ USD and Canada's is $\$ 4,754.95$ USD (17). Despite all countries across Africa pledging during the Abuja Declaration of 2001 to spend at least $15 \%$ of their annual budget on healthcare, 10 years later only one country has achieved this milestone; and the best estimates today indicate only 10 countries across Africa have met this goal $(18,19,20)$. Due, in part, to a lack of funding, many hospitals in sub-Saharan Africa are already operating beyond designated capacity, with sometimes double the number of patients allowed in wards and multiple patients sharing a bed, translating to huge workloads for healthcare staff (21). In the midst of the pandemic, healthcare workers in the Democratic Republic of Congo, Kenya, Nigeria, Sierra Leone, and Zimbabwe have gone on strike demanding adequate protective gear and fair pay $(15,22)$.

The level of support governments across Africa have offered their people to better manage the devastating effects of Covid-19 differs from country to country. In some countries, government officials have gone so far as to not acknowledge the existence of Covid-19 within their borders which in turn has hampered efforts to address the pandemic (23). In Tanzania, for example, government officials declared victory over the pandemic just one month after reporting 509 cases and 21 deaths related to the disease, refused to work with external bodies to monitor the situation, and have not published information on any new cases of Covid-19 since May 8, 2020.

Responses to Covid-19 by other African countries have been marred by mismanagement of resources and corruption (23, 24). In Kenya, for example, there has been an outcry from the medical fraternity, civil society, citizens, and the international community over the mismanagement and corruption surrounding Covid-19 resources (24). This is an indictment of the government of Kenya which had shown promise of readiness to battle Covid- 19 by rescuing vulnerable families and the elderly, expansion of bed capacities in hospitals, and cushioning the horticulture industry and small-scale farmers (21). On the other hand, some countries across Africa have done an admirable job. For instance, Rwanda implemented strict lockdowns, offered free diagnostic testing, designated particular clinics to be quarantine centres, and mobilised community healthcare workers, police, and college students to serve as contact tracers (25). And, of course, we cannot forget the impressive job by Africans at the African Union, the Africa CDC, and at the WHO through provision of essential services and funds, preventing and controlling infection, supporting African governments, surveillance and communication of risk, treatment and providing general information that aims towards addressing the Covid-19 pandemic in the continent $(26,27)$.

Such noble efforts notwithstanding, the experience of most 
people in Africa is vastly different from that of people living in HICs such as Canada. A disproportionately large number of people in the global South are living in extreme poverty, without access to clean water, adequate shelter, and adequate healthcare. What's more, some of these places are also affected by civil and political unrest, experience more severe natural disasters (such as pest infestations, floods, and droughts), and are battling neglected tropical diseases. Without access to basic human goods, it is impossible to adhere to basic Covid19 prevention guidelines - people cannot wash their hands if they do not have water, stay home without food, observe social distancing while living in crowded dwellings, and wear masks if they cannot afford them. Even for the many people who are able to meet their most basic human needs, inadequate access to electricity and the internet makes working from home a significant challenge (28). The vast majority of people living in the global North do not have to contend with these challenges.

Due to these challenges, public health experts initially expressed disquiet regarding high projected Covid-19 infection and mortality rates across Africa. For example, early modelling studies from the Imperial College of London in April 2020 suggested that, under the best-case scenario, Africa would witness 122 million infections, and 300,000 deaths in 2020 due to Covid-19 (3). Surprisingly, as of September 1, 2021, Africa has reported approximately 7.8 million cases of Covid19 and just over 199,000 related deaths, and as mentioned earlier, some of the countries are on track to managing Covid19 quite well, despite their limited ability to follow the WHO's guidance due to existential challenges $(29,30)$ - absence of substantial financial investments and of robust and integrated healthcare systems. This situation warrants scientific studies to explain this resilience and calls for a broader understanding of health and healing beyond a strictly biomedical approach. We acknowledge that this trend may be reversed in future waves of the pandemic, but, based on WHO official reporting, the data suggest a relatively low rate of Covid-19 infection and mortality across Africa in comparison to the global North, as of August 27, 2021 (31).

\section{The consciousness of being "all in this together"}

More than a year since the Covid-19 outbreak, both the global North and the global South remain vulnerable. Covid-19 has revealed critical and conflicting realities about these regions that were hitherto ignored and have since emerged. The global North has, in general, robust and well-integrated healthcare systems and social services that assist individuals suffering the indirect effects of Covid-19. In the global South, the pandemic has created a huge strain on already struggling healthcare systems and dragged down economic growth (32). While the global North has suffered more Covid-19 infections and mortalities than sub-Saharan Africa over the last one year, the latter has suffered more indirect effects in form of more devastation of the always dilapidated healthcare systems, crumbing of the economic systems and exacerbation of ills that have bedevilled the continent like famine and lack of basic necessities of life.

One of the factors that precipitated the emergence and spread, and mismanagement of disease outbreaks is a repeated failure to accept the responsibilities we share as a global community. In the current context, effective management of Covid-19 requires two key responses: strengthening health systems and seeking to understand why sub-Saharan Africa has registered much lower cases of Covid-19. Many theories exist; for example, some point to the generally warmer climate, non-biomedical healing practices, communal living, the youthful African population, and the experience of handling epidemics such as HIV and Ebola. But little evidence is available on any of these views. Yet, a good pandemic response is not exclusively a health system responsibility; individuals and communities also have an important role to play. While WHO defines health as a state of complete physical, mental, and social well-being and not merely the absence of disease or infirmity (33), the social perspectives have remained theoretical because the emphasis is on the physical and mental aspects of health. Africa's indigenous worldviews and epistemologies might hold the key to improving health outcomes worldwide. These strengths need to be studied and applied elsewhere for effective management of the pandemic.

Saying that we are together without acknowledging the potential contribution from all is disingenuous. For us to truly be "all in this together" two things need to happen: (i) government and policy decision-makers in HICs should provide aid to their own people as well as to LMICs during the pandemic, and (ii) government and policy decisionmakers in LMICs must recognise and do all they can to support their own people, which includes the responsibility to be good stewards of important resources. LMICs that have shown great resilience to the pandemic with minimal resources can contribute by studying and understanding how they were able to better resist the first and second waves of the Covid-19 ravages and to share this invaluable wisdom with the rest of the world. Of great concern is the profiling and stigmatisation due to Covid-19 experienced in both HICs and LMICs - China has been accused of profiling Africans in China and Africans have profiled the Chinese in Africa (34). Perhaps by the continuous show of ability to survive the effects of Covid-19 with few resources, LMICs have a chance to make a substantial contribution on alternative approaches to tackling this and other pandemics. Specifically, we can view the varied contributions of the global North and global South to the management of the pandemic.

\section{Contribution of HICs during Covid-19}

In order for HICs to claim that we are "all in this together" in any meaningful sense, they should continue providing direct support to all people living within their borders, including permanent residents, migrants, refugees, temporary foreign workers, and in addition, they must provide greater aid to 
those people in need in the global South. For an essential part of what it means for countries to be unified and in solidarity with one another is to help minimise the suffering experienced by one another. No moral argument or justification is required to ground such a requirement; rather, simple common-sense and an appeal to our shared humanity should suffice. For many countries in the global North, authentic practice of "all in this together" requires shifting their thinking and strategy from "my country first" (nationalistic) to a more communal and egalitarian one. Consideration and engagement with the African social philosophy of ubuntu, which seeks to honour the dignity and integrity that all humans possess by virtue of being human and in relationship with one another would be insightful (35). Ubuntu has its focal point not in nationhood or self-interest, or "us" versus "them", but in the communal good and common humanity (35). A global pandemic like Covid-19 may afford an opportunity for all to embrace the spirit of Ubuntu. This is not just a matter of belief but an active demonstration of the interconnectedness of all human beings, irrespective of where they live (35).

Indisputably, HICs have a duty to collaborate with LMICs in the fight against Covid-19 by providing more generous aid than they did prior to the pandemic. Furthermore, HICs should not be procuring far more vaccines, diagnostics, and therapeutics for their own populations than are needed. For example, Canada's recent procurement strategy to obtain more than 425 million doses of vaccines for Covid-19 (ie, more than 111 doses per person) prevents other countries from accessing lifesaving prophylactics (36). Such a tactic - even if excess vaccines are donated to LMICs at a later date - is hardly in the spirit of solidarity. Truly being all in this together means focusing on ensuring that those individuals most at risk of severe disease and death, irrespective of where they live, have access to Covid-19 vaccines before those less at risk and the general populations.

\section{Contribution of LMICs during Covid-19}

As of now, LMICs cannot make similar material contributions to fighting the pandemic, but they can contribute by striving for best practices for minimising the spread of disease and by combating misinformation that is likely to lead to adverse health outcomes. LMICs should encourage and take part in research on prophylactics, diagnostics, and therapeutics for Covid-19 to help ensure that people in the global South have vaccines, tests, and treatments that work for them. Further, LMICs should ensure that only evidence-based medical products, including traditional medicines, are utilised in the fight against the disease (37). Finally, when it comes to economic aid and social supports, priority should be given to the most vulnerable individuals and groups - including children, women, and the poor - when a minimum social safety net cannot be provided to all.

One special attribute specific to Africa is the philosophy of Ubuntu mentioned earlier. Over and above its inspirational trait of encouraging the world to live in solidarity, Ubuntu has been a source of social therapy during the current times when the global clarion call was about "social distancing." Through Ubuntu, people who could not access information about Covid-19 from the media (print, electronic, or mass media) obtained the information from the people they interacted with through communalism. Better still, some families from poor backgrounds have not starved because they have maintained community support within their settings. During the initial lockdown in Kenya, when Covid-19 struck, some people joined together in a campaign dubbed "adopt-afamily" which basically was about individuals or small groups of people identifying families in need and providing them with life necessities such as food (38). Such gestures are examples of what Africa can contribute to HICs.

Covid-19 experiences in Africa suggest that an effective response to a global epidemic comprises a holistic handling of a health situation beyond biomedicine to engage communities. Past experience with epidemics in Africa suggests that engaging with communities on the contextual details and knowledge of what has worked before is indispensable (34). Scientific solutions do not work in isolation.

Africans refer to the indigenous concept of spirituality as a key source of their resilience. From an African perspective, spirituality is essentially about healthy relationships with the supernatural, with the self, with other persons, and with the rest of creation including inanimate things. The feeling of integral connectedness of beings gives human beings a sense of security in the face of devastating and deadly tragedies like the Covid-19 pandemic. They draw strength, hope, and assurance for overcoming the scourge from this connectedness of all beings around them standing in support, bringing a unique sense of being "all in this together". It is common to find Africans appealing to the supernatural forces to intervene against the pandemic or use some traditional remedies like herbs in the effort to prevent infection from Covid-19. This mindset points to the usefulness of indigenous wisdom beyond science and reason in promoting human resilience.

Rather than insisting on the difficulty of applying tangible and objective measures in such invisible realities as spirituality, it would make sense to identify and promote communal values not only in preparation for future epidemics but also for future Covid-19 waves and resurgences. The following would be relevant research questions: how do humans cultivate hope in the context of vulnerability and in the midst of crisis? How does hope promote health? Indigenous African communities relied on hope gained from oral forms of wisdom including narratives, proverbs, and riddles. These would console and build stoic courage to become the basis for resilience when faced with devastating experiences. This is not the kind of demonstration of supremacy of human potential by virtue of a superior rational faculty couched in the ideas of Spinoza and his like-minded Enlightenment philosophers. The 
African indigenous style of adapting to disaster was communal and oral (39). The Covid-19 experience saw the return of such practices in contemporary Africa; for example, narratives and jokes shared on social media kept people diverted from the ravages of Covid-19, thereby promoting resilience. All these are forms of non-biomedical indigenous healing practices that create a kind of "herd immunity".

\section{The duty of LMICs and HICs to work together}

In a truly just world, there would be no HICs and no LMICS and no unfair asymmetries. Being in all this together means working together towards a truly just world in which the basic needs of all are met. In the context of Covid-19, a just world would recognise the fundamental contributions of all in the management of the pandemic. LMICs would share with the world what they have gathered from experience with prior epidemics and the socio-pragmatic realities that address unique contexts; while HICs would share with the world the financial and material resources required to build effective healthcare systems. With contributions from both, the current Covid-19, and future epidemics, may be effectively managed.

A major challenge to working together is a lack of trust. Intuitively, we know what it means to work well together and in good faith for a common cause or noble goal. Likewise, we know intuitively what it means to not work well together or to work together in bad faith, or to advance our own private agenda. History is filled with both kinds of examples, and now, perhaps more than ever, LMICs and HICs need to work together in a harmonious manner. For LMICs, working together positively requires relationships and partnerships of trust without LMICs assuming some kind of foreign agenda on the part of the global North, merely because past collaborations were characterised by violations of human rights and atrocities (40). If we are going to tackle Covid-19 worldwide effectively, we need to ensure that the overwhelming majority of people across the world are vaccinated. This will be extremely hard to achieve if many people in the global South believe that the West created and spread Covid-19 as a "means of population control" or that the West wants to "control mankind with the use of microchip implants or digital tattoos"(41).

For HICs, working well together means using any power or privilege possessed for the global good and for the equitable distribution of diagnostic tests, vaccines, therapeutics, medical supplies, and aid. The fact that, for example, the United States bought most of the world's supply of Remdesivir for national use or that some HICs across the world are using their wealth and power to enter into contracts with vaccine manufacturers to ensure they get a vaccine before others is unacceptable (42). HICs need to demonstrate good faith, and work toward ensuring that the distribution of resources required to combat Covid-19 is not based on power, wealth, or privilege. Fundamentally, HICs must also work toward levelling the playing field and creating a more just society now, so that in future pandemics, LMICs will be well-equipped to aid their own citizens without any need for external help. Doing so, we contend, is likely to bring more LMICs on board in the fight against Covid-19 and help tackle conspiracy theories, reluctance, and refusal, as well as to help address vaccine hesitancy.

\section{Conclusion}

As we have shown, being "all in this together" requires HICs and LMICs to meaningfully work together to reduce the negative impact of Covid-19 worldwide. Saying that we are "all in this together" without actions aimed at addressing global health inequities is empty and do little good to anyone, except perhaps to those people who feel good by reiterating such a refrain or those who use such a refrain to garner support for particular initiatives and private agendas. Since the beginning of the global pandemic, there has been much talk by policy makers, governments, and stakeholders about solidarity, and some, no doubt, have provided and continue to provide generous aid to those in need. The global pandemic is still progressing and getting worse in some parts of the world, and there is much aid that needs to be provided and much good to be done. Solidarity and morality require not just saying the correct things, but doing the right things. The time to act is now.

Conflicts of interest and funding: None to declare. The authors have not published any other similar work.

\section{References}

1. WHO Coronavirus Disease (COVID-19) Dashboard. [Cited 2021 September 5]. Available from: https://covid19.who.int/

2. World Health Organization. WHO Director-General's opening remarks at the World Health Assembly. 2020 May 18[cited 2020 May 25]. Available from: https://www.who.int/dg/speeches/detail/whodirector-general-s-opening-remarks-at-the-world-health-assembly

3. Roberton T, Carter ED, Chou VB, Stegmuller AR, Jackson BD, Tam Y, et al. Early estimates of the indirect effects of the COVID-19 pandemic on maternal and child mortality in low-income and middle-income countries: a modelling study. Lancet Glob Health . 2020 May 12 [cited 2020 May 25];0(0). Available from: https://www.thelancet.com/ journals/langlo/article/PIIS2214-109X(20)30229-1/abstract

4. Wan W.The coronavirus pandemic is pushing America into a mental health crisis. Washington Post. 2020 May 4[cited 2020 Jun 11]. Available from: https://www.washingtonpost.com/health/ 2020/05/04/mental-health-coronavirus/

5. Huster K. We're all in this together: Coronavirus lessons from Hong Kong. Doctors Without Borders - USA. 2020 Mar 4[cited 2020 Aug 14]. Available from: https://www.doctorswithoutborders.org/what-wedo/news-stories/story/were-all-together-coronavirus-lessons-hongkong

6. Guterres A. We are all in this Together: Human Rights and COVID-19 Response and Recovery . United Nations; 2020 Apr 23 [cited 2020 Jun 16]. Available from: https://www.un.org/en/un-coronaviruscommunications-team/we-are-all-together-human-rights-andcovid-19-response-and

7. Canada Public Health Services. Coronavirus disease (COVID-19): Outbreak update 2020 [cited 2021 Sep 5]. Available from: https:// www.canada.ca/en/public-health/services/diseases/2019-novelcoronavirus-infection.html

8. MacCharles T. $82 \%$ of Canada's COVID-19 deaths have been in longterm care, new data reveals thestar.com. 2020 May 7 [cited 2020 Jun 18]. Available from: https://www.thestar.com/politics/federal/ 2020/05/07/82-of-canadas-covid-19-deaths-have-been-in-longterm-care.html

9. Taekema D. Here's how to build a COVID-19 pandemic response unit in just 14 days. CBC News. 2020 Apr 2[cited 2020 Jul 9]. Available from:https://www.cbc.ca/news/canada/hamilton/covid-josephbrant-blt-construction-pandemic-unit-1.5518090 
10. Staff, Canadian Press. CAE ventilator receives Health Canada certification, starts shipping. Global News. 2020 Jun 17 [cited 2020 Jul 9]. Available from: https://globalnews.ca/news/7077957/caeventilators-canada-coronavirus/

11. Staff, Canadian Press. Canada almost self-sufficient in PPE as Canadian businesses step up: PM 2020 Jun 26 [cited 2020 Jul 9]. Available from: https://www.cbc.ca/news/politics/canada-ppe-covid19-1.5628237

12. Canada Department of Finance. Canada's COVID-19 Economic Response Plan. 2020 [cited 2020 Jun 19]. Available from: https:// www.canada.ca/en/department-finance/economic-responseplan.html

13. Government of Canada. COVID-19: Financial assistance for newcomers, temporary residents and refugees. 2020 [cited 2021 Mar 20]. Available from: https://www.canada.ca/en/immigration-refugeescitizenship/services/coronavirus-covid19/financial-assistance.html

14. Verhagen LM, de Groot R, Lawrence CA, Taljaard J, Cotton MF, Rabie H. COVID-19 response in low- and middle-income countries: don't overlook the role of mobile phone communication. Int J Infect Dis. 2020 Aug 4 [cited 2020 Aug 28]; Available from: http:// www.sciencedirect.com/science/article/pii/S1201971220306251

15. Africa News. Africa's coronavirus cases hits half a million, about 12,000 deaths. Africanews. 2020 [cited 2020 Jul 13]. Available from: https:// www.africanews.com/2020/07/08/africa-s-coronavirus-deaths-pass1000-mark/

16. Deaton AS, Tortora R. People In Sub-Saharan Africa Rate Their Health And Health Care Among Lowest In World. Health Aff Proj Hope. 2015 Mar;34(3):519-27.

17. World Bank. Current health expenditure per capita (current US\$) World, Canada | Data. [cited 2020 Jul 15]. Available from: https:// data.worldbank.org/indicator/SH.XPD.CHEX.PC.CD?locations=1WCA\&name desc $=$ false

18. Kiross GT, Chojenta C, Barker D, Loxton D. The effects of health expenditure on infant mortality in sub-Saharan Africa: evidence from panel data analysis. Health Econ Rev. 2020 Mar 6;10(1):5.

19. World Health Organization. The Abuja Declaration:Ten Years On. WHO; [cited 2020 Aug 11]. Available from: https://apps.who.int/iris/ bitstream/handle/10665/341162/WHO-HSS-HSF-2010.01-eng.pdf? sequence $=1$ \&isAllowed $=y$

20. Staff. South African Institute of International Affairs. SADC and the Abuja Declaration: Honouring the Pledge [cited 2021 Sep 5] Available from:https://saiia.org.za/research/sadc-and-the-abuja-declarationhonouring-the-pledge/

21. Kapata N, Ihekweazu C, Ntoumi F, Raji T, Chanda-Kapata P, Mwaba P, et al. Is Africa prepared for tackling the COVID-19 (SARS-CoV-2) epidemic? Lessons from past outbreaks, ongoing pan-African public health efforts, and implications for the future. Int J Infect Dis. 2020 Apr; 93:233-6.

22. Makoni M. COVID-19 worsens Zimbabwe's health crisis. Lancet. 2020 Aug 15;396(10249):457.

23. Houreld K, Lewis D. In Africa, lack of coronavirus data raises fears of "silent epidemic" | Cape Breton Post. 2020 Jul 8 [cited 2020 Jul 15]. Available from: http://www.capebretonpost.com/news/world/inafrica-lack-of-coronavirus-data-raises-fears-of-silent-epidemic470787/

24. Kwayu AC. Tanzania's COVID-19 response puts Magufuli's leadership style in sharp relief. Conversation. 2020 May 31[cited 2020 Jul 15]. Available from: http://theconversation.com/tanzanias-covid-19response-puts-magufulis-leadership-style-in-sharp-relief-139417

25. Beaubien J. Why Rwanda Is Doing Better Than Ohio When It Comes To Controlling COVID-19. NPR.org. 2020 Jul 15[cited 2020 Aug 12]. Available from: https://www.npr.org/sections/goatsandsoda/ 2020/07/15/889802561/a-covid-19-success-story-in-rwanda-free- testing-robot-caregivers

26. African Union. African Union: AU COVID-19 Response Fund. [cited 2021 Aug 30]. Available from https://au.int/en/ aucovid19responsefund

27. WHO Africa. Covid-19 in Africa: Response areas. [cited 2021 Aug 30] Available from https://www.afro.who.int/covid-19-africa-responseareas

28. Akrofi MM, Antwi SH. COVID-19 energy sector responses in Africa: A review of preliminary government interventions. Energy Res Soc Sci. 2020 Oct; $68: 101681$.

29. Africa CDC. Africa CDC - COVID-19 Daily Updates. [cited 2021 Sep 5]. Available from: https://africacdc.org/covid-19/

30. World Health Organization. A guide to WHO's guidance on COVID19. [cited 2020 Sep 10]. Available from: https://www.who.int/newsroom/feature-stories/detail/a-guide-to-who-s-guidance

31. World Health Organization. WHO Coronavirus (COVID-19) Dashboard. 2021 Aug 27 [cited 2021 Aug 30]. Available from https:// extranet.who.int/publicemergency

32. Gondwe G. Assessing the Impact of COVID-19 on Africa's Economic Development. 2020 Jul [cited 2021 Sept 25] Available from: https://unctad.org/system/files/official-document/aldcmisc2020d3 en.pdf

33 World Health Organization Constitution. [cited 2021 Sep 5] Available from: https://www.who.int/about/who-we-are/ constitution

34. Human Rights Watch. China: Covid-19 Discrimination Against Africans: Forced Quarantines, Evictions, Refused Services in Guangzhou. 2020 May [cited 2021 Sept 25] Available from: https:// www.hrw.org/news/2020/05/05/china-covid-19-discriminationagainst-africans

35. Molefe M, Magam N. What Can Ubuntu Do? A Reflection on African Moral Theory in Light of Post-Colonial Challenges. Politikon. 2019 Jul 3;46(3):311-25.

36. Government of Canada. Procuring vaccines for COVID-19. 2020 [cited 2021 Mar 28]. Available from: https://www.canada.ca/en/ public-services-procurement/services/procuring-vaccinescovid19.html

37. World Health Organization. WHO supports scientifically proven traditional medicine. Regional Office for Africa. 2020 May 4[cited 2020 Jul 29]. Available from: https://www.afro.who.int/news/whosupports-scientifically-proven-traditional-medicine

38. Ombuor R. Kenya's 'Adopt a Family' campaign pairs wealthy with less fortunate during COVID lockdown. VOA News. 2020 Jun 29[cited 2020 Aug 13]. Available from: https://www.voanews.com/africa/ kenyas-adopt-family-campaign-pairs-wealthy-less-fortunateduring-covid-lockdown

39. Lloyd G. Hope and Optimism: A Spinozist Perspective on COVID-19. Bioethical Inquiry.2020 Dec; 17: 503-6. Doi: https://doi.org/10.1007/ s11673-020-10028-5.

40. Saha S, Kavattur P, Goheer A. The C-Word: legacy of colonialism. Health Systems Global. 2019 Apr 26 [cited 2020 Jul 31]. Available from: https://healthsystemsglobal.org/news/the-c-word-tacklingthe-enduring-legacy-of-colonialism-in-global-health/

41. Horner B. False Bill Gates conspiracy theories echo through Africa. Japan Times. 2020 [cited 2020 Jul 31]. Available from: https:// www.japantimes.co.jp/news/2020/05/28/world/bill-gatesonspiracy-theories-africa/

42. Tumilty R. Canadian government announces deal with two leading COVID-19 vaccine candidates. National Post. 2020 Aug 5[cited 2020 Aug 28]. Available from: https://nationalpost.com/news/canada/ canadian-government-announces-deal-with-two-leading-covid-19vaccine-candidates 